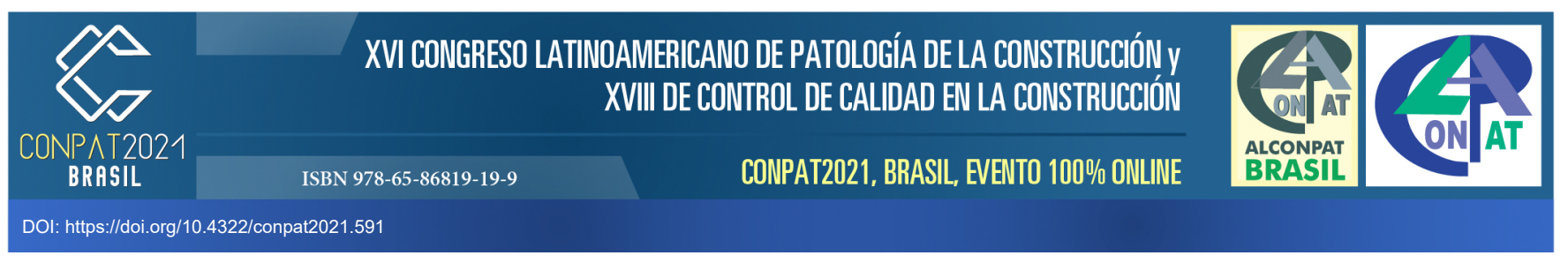

\title{
Avaliação das Propriedades Mecânicas do Concreto ao Substituir Frações do Agregado Miúdo por Borracha De Pneu
}

\author{
MR. Caetano ${ }^{1 *}$, KA. da Cruz ${ }^{1}$, NS. Aguiar ${ }^{1}$, OG. Teixeira $^{2}$ \\ *Autor de Contacto: caetano.mr@outlook.com \\ ${ }^{1}$ Discente de Engenharia Civil do Centro Universitário FG (UniFG), Guanambi, Brasil \\ ${ }^{2}$ Docente de Engenharia Civil do Centro Universitário FG (UniFG), Guanambi, Brasil
}

\begin{abstract}
RESUMO
A extração de matéria prima e produção de materiais da construção civil bem como a produção da borracha de pneu, produz elevado impacto ambiental. Desse modo, o presente trabalho busca analisar a incorporação da borracha de pneu no concreto, através da sua transformação em agregado miúdo, além de avaliar suas propriedades mecânicas quando submetido a tensões de tração e compressão. Os ensaios consistiram em substituir parcelas do agregado miúdo por borracha em um traço de concreto com resistência padrão de $20 \mathrm{MPa}$ e observar se atende a referida resistência. Ao se analisar as propriedades dos corpos de prova submetidos a compressão e tração por compressão diametral, observou-se que houve redução da resistência quando substituído o agregado miúdo convencional por borracha.
\end{abstract}

Palavras chave: Sustentabilidade; Construção Civil; Concreto; Resistência.

\section{RESUMEN}


La extracción de materias primas y la producción de materiales de construcción, así como la producción de caucho para neumáticos, produce un alto impacto ambiental. Así, el presente trabajo busca analizar la incorporación del caucho de neumáticos en el hormigón, a través de su transformación en áridos finos, además de evaluar sus propiedades mecánicas al ser sometido a tensiones de tracción y compresión. Las pruebas consistieron en reemplazar porciones del agregado fino con caucho en una mezcla de concreto con una resistencia estándar de $20 \mathrm{MPa}$ y observar si cumple con esta resistencia. Al analizar las propiedades de probetas sometidas a compresión y tracción por compresión diametral, se observó que hubo una reducción en la resistencia cuando se reemplazó el agregado fino convencional por caucho.

Palabras clave: Sustenibilidad; Construcción civil; Hormigón; Resistencia.

\begin{abstract}
The extraction of raw materials and production of construction materials, as well as the production of tire rubber, produces a high environmental impact. Thus, the present work seeks to analyze the incorporation of tire rubber in concrete, through its transformation into fine aggregate, in addition to evaluating its mechanical properties when subjected to tensile and compression stresses. The tests consisted of replacing small parts of the aggregate with rubber in a concrete mix with a standard strength of $20 \mathrm{MPa}$ and observing if it meets that resistance. When analyzing the properties of the specimens submitted to compression and traction by diametrical compression, it was observed that there was a reduction in resistance when the conventional fine aggregate was replaced by rubber.
\end{abstract}

Keywords: Sustainability; Construction; Concrete; Resistance.

\title{
1. INTRODUÇÃO
}

Um dos principais problemas enfrentados no século XXI está relacionado a destinação dos resíduos gerado pelos diversos seguimentos das indústrias, responsável pela produção de grandes quantidades de resíduos lançadas no meio ambiente, promovendo um desequilíbrio ambiental. Tais 
aspectos evidenciam a necessidade na qual o ser humano tem em procurar minimizar tais consequências aliado ao desenvolvimento econômico (São Thiago e Bicalho, 2018).

No Brasil, são descartados mais de 30 milhões de pneus por ano, sendo que a maior parte é de forma incorreta. Os pneus que não apresentam utilidade para qual foi criado, geram problemas sanitários e ambientais como: local para procriação de mosquitos, emissão de gazes contaminantes produzidos pela queima da borracha, se for descartado em aterros sanitários dificultam a compactação, reduzido assim a vida útil dos aterros, entre outros (Lagarinhos e Tenório, 2013).

No que tange a construção civil, o consumo de matéria prima para produção de materiais de construção empregados na execução de obras, acarreta um grande impacto no meio ambiente, devido a origem destes. No entanto devido ao avanço das tecnologias e o aperfeiçoamento de recursos e técnicas, a construção civil permite a elaboração e execução de projetos sustentáveis com a possibilidade de inclusão de resíduos sólidos dentro de produtos ou processos de um empreendimento, como a inserção da borracha no concreto (Bravo, 2014).

O concreto é um produto versátil constituído por uma mistura de água, cimento, pedra e areia. Sendo ele um material da construção civil mais utilizado, isso está relacionado a sua alta resistência, viabilidade de moldes e o baixo custo. Quando o concreto é misturado com outras matérias é necessário avaliar as alterações em sua propriedade em relação a resistência à tração, dureza, durabilidade e o módulo de elasticidade (Martins, 2013).

Assim, a utilização do resíduo de pneus como agregado na confecção de concreto vem sendo testada nos últimos anos, na tentativa de demonstrar a sua viabilidade por se tratar da possibilidade de reuso (Boaventura, 2011). Logo, este trabalho tem por objetivou-se a avaliar a possibilidade da utilização de resíduos de borracha de pneus na composição do concreto não estrutural substituindo o agregado miúdo pela borracha em frações graduais, e comparar o desempenho mecânico por meio de ensaios normatizados para diferentes períodos de cura.

\section{PROCEDIMENTO}

A fim de analisar um traço de concreto com o método de dosagem da Associação Brasileira de Cimento Portland (ABCP, 2002) adaptado da ACI 201, foi realizado em laboratório o cálculo para composição de concreto com resistência prevista de $20 \mathrm{MPa}$, onde foi incorporado a borracha em proporções de $0 \%, 2 \%, 4 \%$ e $6 \%$ substituindo em massa o agregado miúdo (areia). Sendo moldado o traço de referência 1: 2,33: 2,46: 0,56 (cimento: areia: brita: água) e os demais traços com a substituição das frações do agregado miúdo.

Inicialmente procedeu-se com o ensaio de caracterização granulométrica do agregado miúdo e graúdo com a finalidade de conhecer a distribuição dos materiais granulares, seguindo o que preconiza a Associação Brasileira de Normas Técnicas através NBR NM 248 (ABNT, 2003). Posteriormente foi determinado a massa específica da areia tendo como parâmetro de execução do ensaio a NM 52 (ABNT, 2009) e para o agregado graúdo seguiu o que preconiza a NM 53 (ABNT, 2009) bem como a massa unitária seguindo as recomendações da NM 45 (ABNT, 2009).

Para a determinação do traço de concreto foram utilizados areia lavada como agregado miúdo, cimento CP II E-32, brita 1 como agregado graúdo, borracha de pneus e água. A borracha foi coletada em uma empresa de recapagem de pneu da cidade de Guanambi-BA e utilizada na mistura como agregado miúdo, cujas partículas não excederam a faixa granulométrica de 4,75 mm. Os materiais utilizados estão ilustrados na Figura 01. 


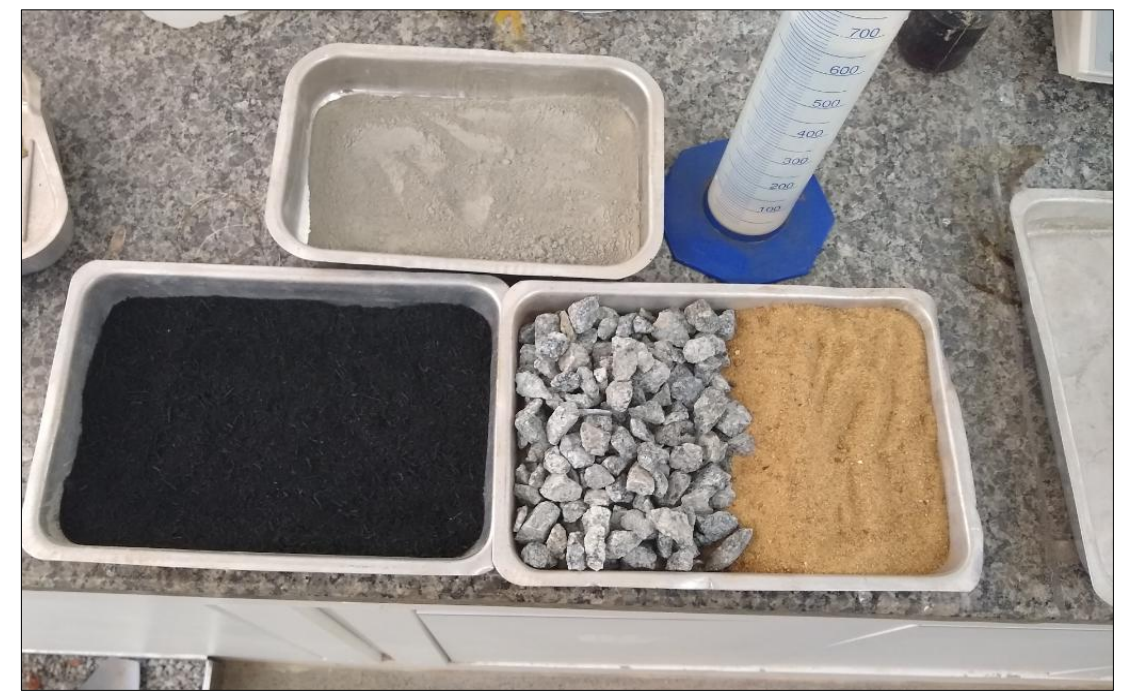

Figura 1. Ilustração dos materiais utilizados nos ensaios. Fonte: Autor, 2021

Após a dosagem, os materiais foram adicionados para mistura em uma betoneira com capacidade para 120 litros, decorrido o período de mistura, foi realizado o ensaio para determinação da consistência do concreto fresco seguindo o que preconiza a norma NBR NM 67 (ABNT, 1998), também chamado de slump test para verificação do abatimento do concreto, tal procedimento foi realizado para todas as composições analisadas. Logo, foram moldados em corpos de prova de dimensões 10 × $20 \mathrm{~cm}$ seguindo do adensamento através de vibrações, conforme determinado pela NBR 5738 (ABNT, 2016). Decorrido o período de 24 horas os corpos de prova foram desmoldados e submetidos a cura úmida para rompimento em idades de 3, 14 e 28 dias.

O ensaio mecânico para rompimento dos corpos de prova nas idades referidas foi realizado em uma prensa hidráulica manual com indicador digital. Foram ensaiados 72 corpos de prova, sendo 18 para cada composição. A determinação da resistência à compressão axial seguiu-se de acordo com a norma NBR 5739 (ABNT, 2018). Para os ensaios de tração por compressão diametral procedeuse de acordo com a NBR 7222 (ABNT, 2011), com o rompimento dos corpos de prova de mesma composição e idades aos de compressão axial.

\section{RESULTADOS}

A partir dos ensaios de peneiramento foi possível traçar as curvas granulométrica dos agregados miúdo (Figuras 2) e graúdo (Figura 3), podendo ser observado a uniformidade da brita e a pouca variação na graduação dos grãos da areia, com vistas a zonas utilizável dos limites superiores e inferiores, conforme estabelece a NBR 7211 (ABNT, 2009). Enquanto os dados obtidos pelos ensaios de massa específica e unitária são descritos na Tabela 1, então, foi possível determinar o modulo de finura da areia podendo classificá-la como areia média. Quanto a caracterização do resíduo da borracha do pneu, dada a uniformidade do elemento e sua composição química independentemente da localização geográfica, empregou-se a caracterização de massa específica e unitária realizada por Simonetti (2020), detalhados na Tabela 2. 


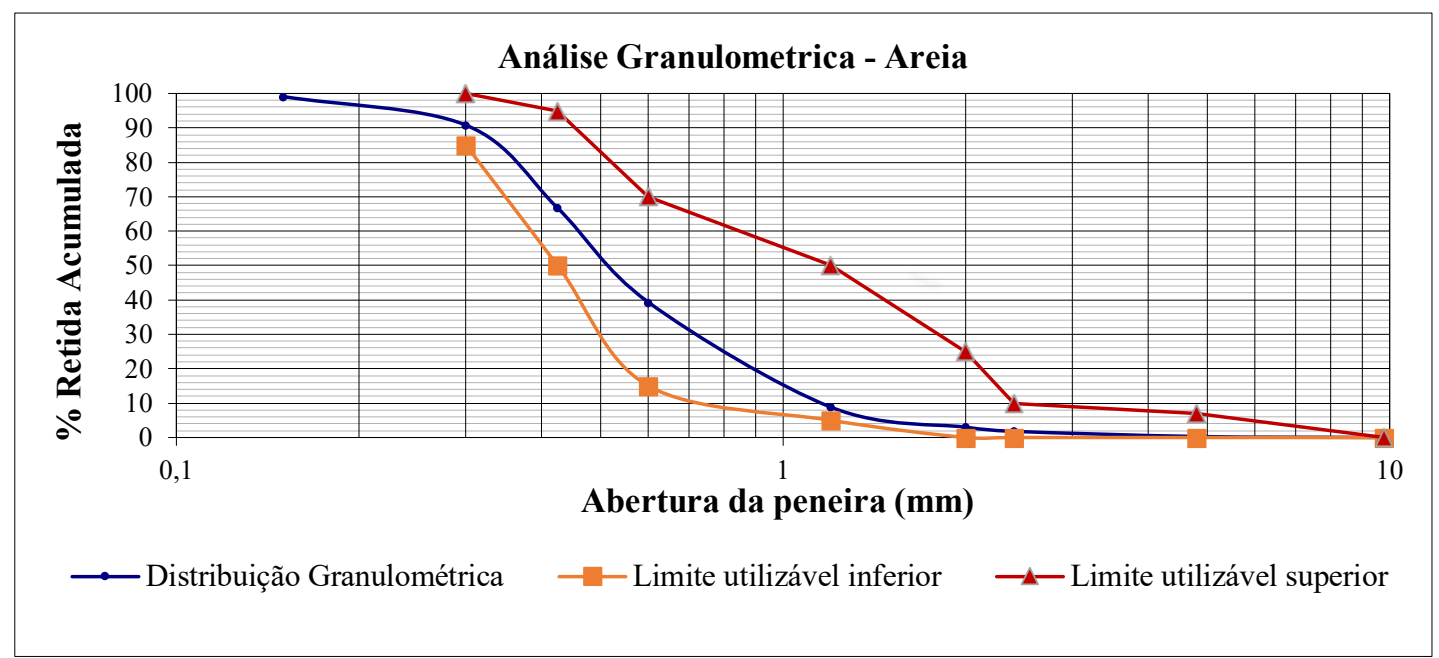

Figura 2. Curva granulométrica do agregado miúdo. Fonte: NBR 7211 (ABNT, 2009), adaptado.

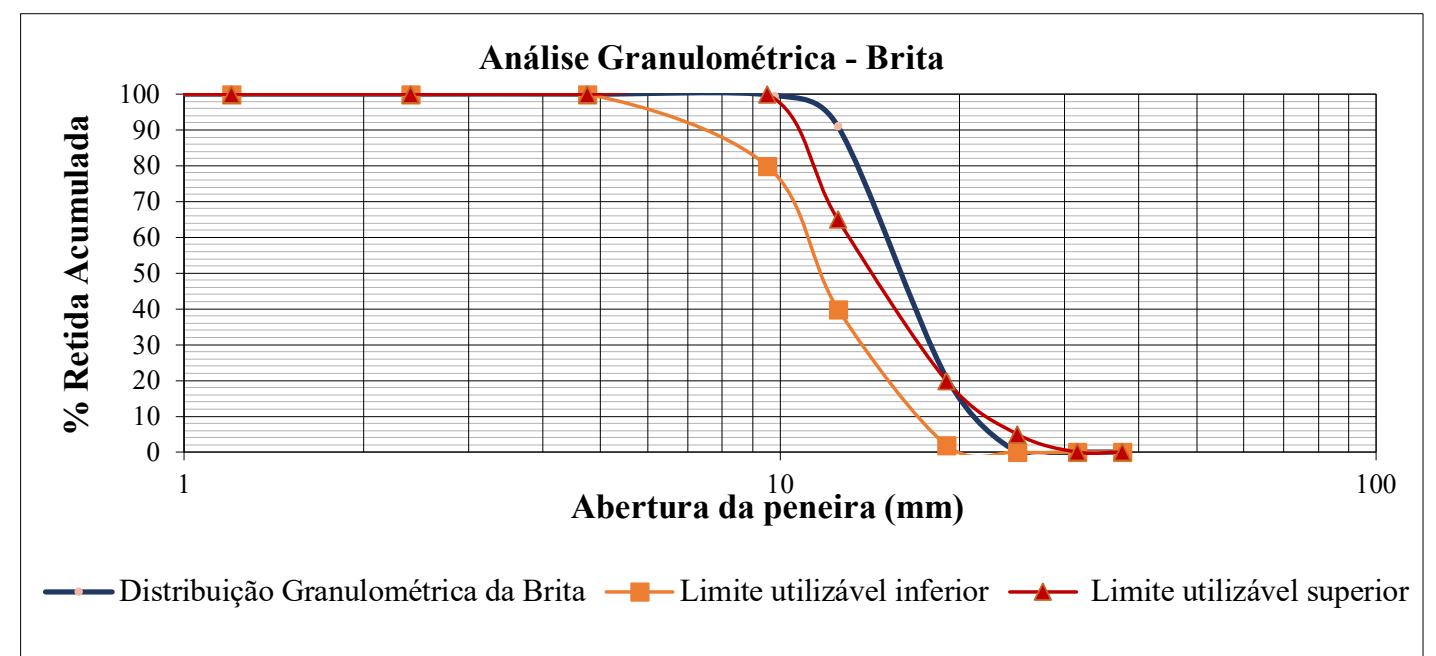

Figura 3. Curva granulométrica do agregado graúdo. Fonte: NBR 7211 (ABNT, 2009, adaptado.

Tabela 1. Valores de massa específica, unitária e modulo de finura para os agregados ensaiados.

\begin{tabular}{|c|c|c|}
\hline Dados & Agregado Miúdo & $\begin{array}{c}\text { Agregado } \\
\text { Graúdo }\end{array}$ \\
\hline Massa Específica & $2,64 \mathrm{~g} / \mathrm{cm}^{3}$ & $2,94 \mathrm{~g} / \mathrm{cm}^{3}$ \\
\hline Massa Unitária & $1,57 \mathrm{~g} / \mathrm{cm}^{3}$ & $1,38 \mathrm{~g} / \mathrm{cm}^{3}$ \\
\hline Módulo de finura & 2,40 & 7,21 \\
\hline
\end{tabular}

Fonte: Autor, 2020.

Tabela 2. Massa unitária e massa específica do resíduo de pneu.

\begin{tabular}{|c|c|}
\hline Dados & $\begin{array}{c}\text { Agregado Resíduo } \\
\text { de Pneu }\end{array}$ \\
\hline Massa Específica & $1,21 \mathrm{~g} / \mathrm{cm}^{3}$ \\
\hline Massa Unitária & $0,54 \mathrm{~g} / \mathrm{cm}^{3}$ \\
\hline
\end{tabular}

Fonte: Simonetti, 2020.

Para os resultados de consistências realizados por meio do ensaio de abatimento de cone, buscouse avaliar a trabalhabilidade dos traços de concreto, os resultados para o traço de referências e os com a substituição do agregado por borracha de pneu, estão detalhados na Tabela 3. Os dados dos 
ensaios, demonstram o aumento do abatimento do concreto trabalhado em relação ao traço de referência a medida em que ocorre a substituição do agregado miúdo, apesar de ocorrer uma redução da trabalhabilidade em relação ao aumento das frações de substituição.

Esse comportamento pode ser justificado pela baixa absorção de água pelo resíduo de borracha, no entanto, a medida em que se substitui frações maiores de agregado por resíduo aumenta a necessidade de água para manter a trabalhabilidade, indicando um aumento na relação água/cimento (Kurz, 2018).

Tabela 3. Relação entre frações de resíduo no concreto e seu abatimento.

\begin{tabular}{|c|c|}
\hline $\begin{array}{c}\text { Frações de Resíduo } \\
\text { de Borracha }\end{array}$ & $\begin{array}{c}\text { Abatimento } \\
\text { (cm) }\end{array}$ \\
\hline $0 \%$ & 9,5 \\
\hline $2 \%$ & 14,0 \\
\hline $4 \%$ & 12,0 \\
\hline $6 \%$ & 10,5 \\
\hline
\end{tabular}

Fonte: Autor, 2021.

Após a moldagem e tempo de cura do concreto para as idades de 3, 14 e 28 dias respectivamente, todos os traços avaliados na resistência a compressão axial tem seus valores expressos na Figura 4. Onde para todos os traços dosado observa-se crescimento na resistência decorrido o período entre testes, entretanto a medida em que se aumenta a porcentagem de adição de borracha de pneu observa-se uma escala menor de aumento da resistência, apesar dos resultados da adição de $6 \%$ ser maior que a frações de $4 \%$, este valor, permanece consideravelmente abaixo do obtido pelo traço de referência e o de substituição de $2 \%$.

Estes valores também podem ser contextualizados com os resultados de abatimento, apesar do decaimento considerável de resistência entre as porcentagens de $4 \%$ e $6 \%$, esses obtiveram abatimento que se aproximam ao ensaio de referência, indicando uma melhor trabalhabilidade para substituições de até $2 \%$, sem grande perda de resistência.

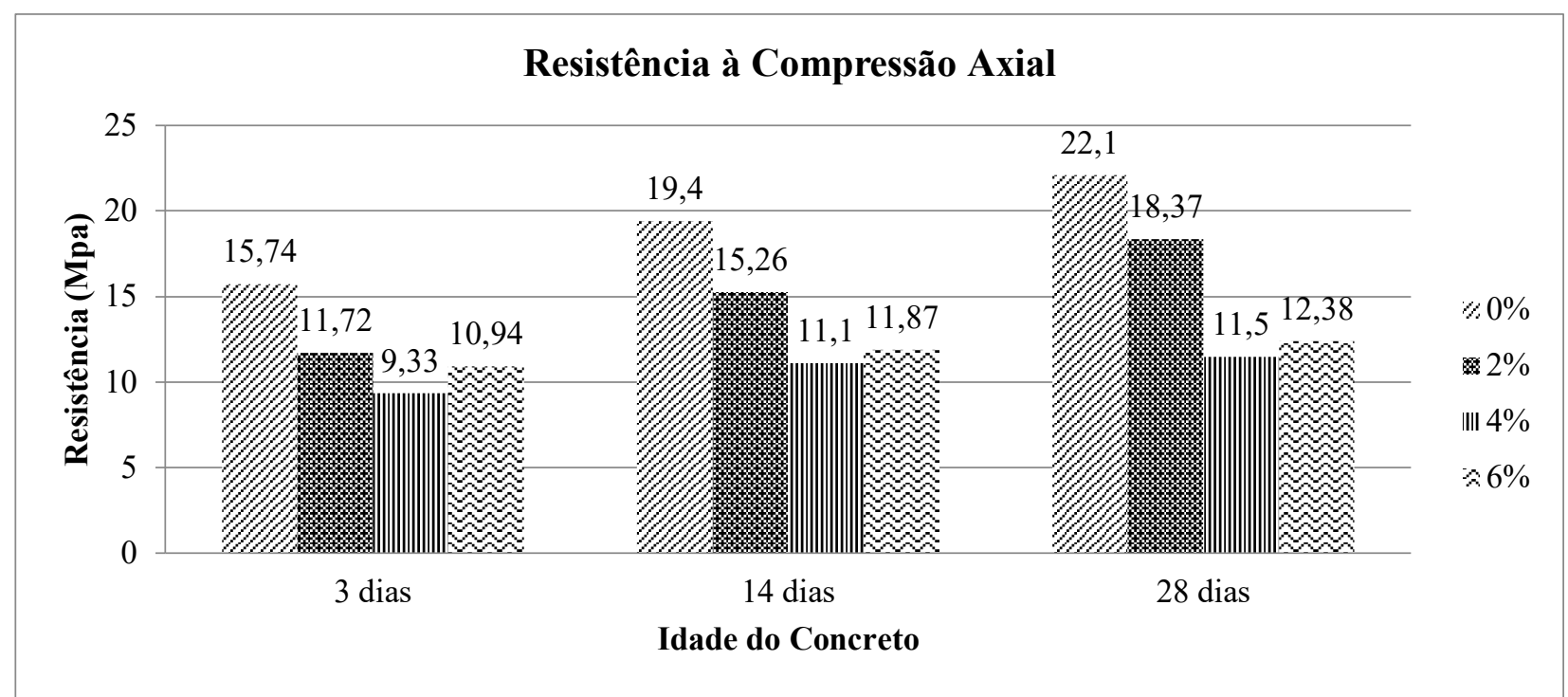

Figura 4. Dados da resistência à compressão dos corpos de prova em suas diferentes idades.

Fonte: Autor, 2020.

Para os ensaios de tração por compressão diametral, observa-se os valores expressos na Figura 5, onde é possível verificar o ganho de resistência entre os períodos de teste para o traço sem 
substituição de borracha, enquanto ao substituir 2\% do agregado miúdo, os valores para a resistência à tração da idade de 3 dias superam os demais testes, mantendo o ganho de resistência para 14 dias e decaindo aos 28 dias. Este comportamento de aumento da resistência à tração até 14 dias e diminuição aos 28 dias também foram observados nas composições de $4 \%$ e $6 \%$ de substituição.

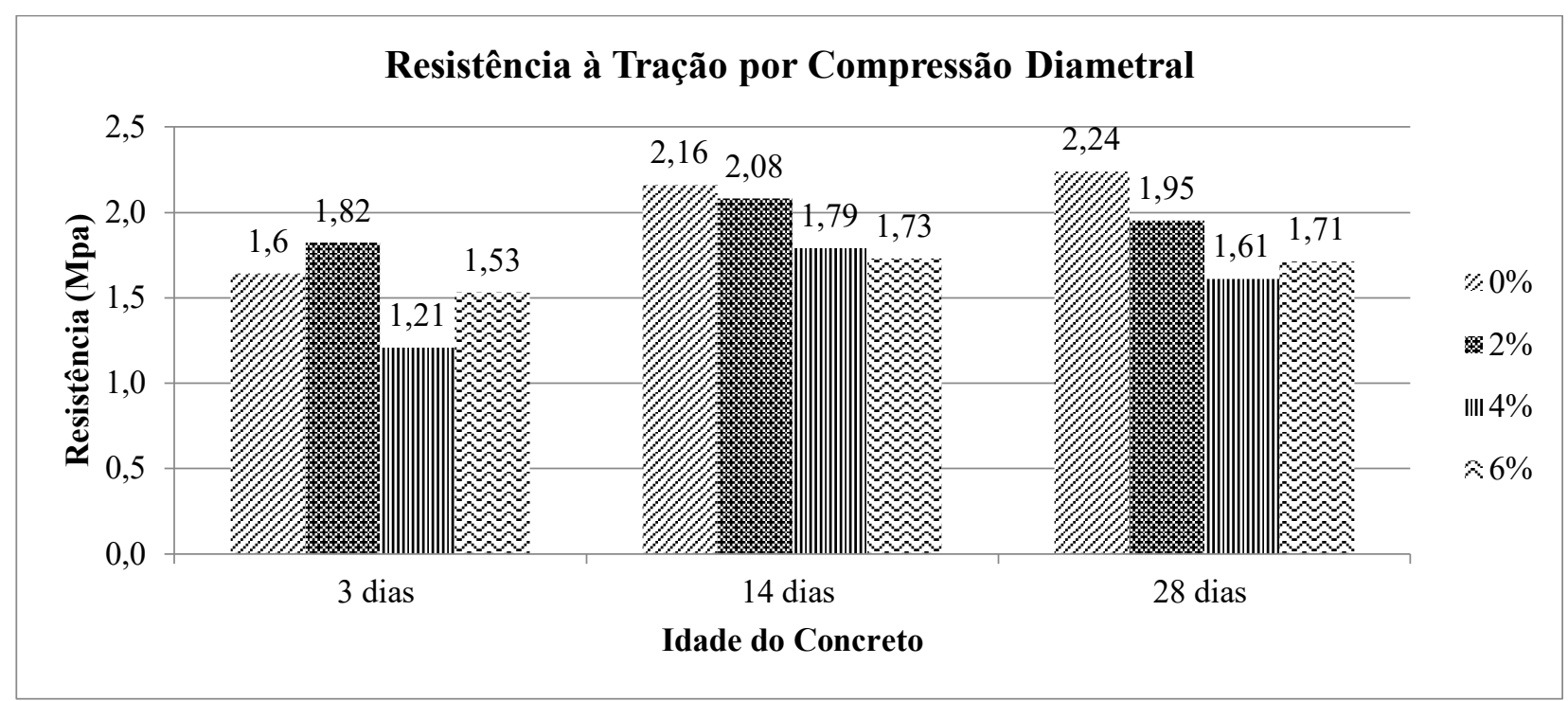

Figura 5. Análise da resistência à tração dos corpos de prova em suas diferentes idades.

Fonte: Autor, 2020.

É possível identificar a relação de perda de resistência com a adição de borracha, mesmo que os valores apresentam resistência crescente em suas composições em cada idade, quando comparado com o traço de referência para resistência prevista de $20 \mathrm{MPa}$ observa-se queda nestes valores, conforme mostra a Tabela 4.

Tabela 4. Relação de porcentagem da perda de resistência nas composições com borracha comparado ao traço de referência.

\begin{tabular}{|c|c|c|c|c|c|c|}
\hline \multirow{2}{*}{ Idade } & \multicolumn{2}{|c|}{$\mathbf{2 \%}$} & \multicolumn{2}{c|}{$\mathbf{4 \%}$} & \multicolumn{2}{c|}{$\mathbf{6 \%}$} \\
\cline { 2 - 7 } & Compressão & Tração & Compressão & Tração & Compressão & Tração \\
\hline 3 dias & $-25,54 \%$ & $10,97 \%$ & $-40,72 \%$ & $-26,21 \%$ & $-30,50 \%$ & $-6,71 \%$ \\
\hline 14 dias & $-21,34 \%$ & $-3,70 \%$ & $-42,78 \%$ & $-17,13 \%$ & $-38,81 \%$ & $-19,90 \%$ \\
\hline 28 dias & $-16,76 \%$ & $-12,95 \%$ & $-47,94 \%$ & $-28,12 \%$ & $-43,90 \%$ & $-23,66 \%$ \\
\hline
\end{tabular}

Fonte: Autor, 2020.

Esse comportamento de redução da resistência a compressão a medida em que se adiciona borracha de pneu, também foi observado por Verzegnassi et al (2011), em seu trabalho com adição de 1\%, $3 \%$ e $6 \%$ de borracha de pneu no concreto convencional em relação a massa do cimento, apesar do critério de incorporação do resíduo diferente deste trabalho a semelhança de comportamento ocorre somente na compressão, enquanto para a tração, o autor observou melhora neste comportamento mecânico em relação ao seu traço de referência.

Em análises da resistência mecânica da argamassa com adição de resíduo de pneu, Kurz (2020) observou o comportamento de redução da resistência a compressão nas composições estudadas. Indicando um comportamento padrão de redução dessa resistência em elementos cimentícios ao ser incorporado resíduo da borracha do pneu. 


\section{CONCLUSÃO}

A partir da análise realizada das propriedades mecânicas do concreto aqui abordadas, com e sem a substituição do agregado miúdo pela borracha, observou-se que apenas o ensaio com a composição de referência, obtiveram aos 28 dias resistência igual ou superior a $20 \mathrm{MPa}$, conforme esperado, enquanto as composições de traços com substituição de borracha ficaram abaixo dessa marca.

Comparando-se os traços de concreto estudado com a substituição da borracha, o traço que apresentou melhor desempenho foi o de 2\% de borracha, com resistência de 17,21 MPa aos 28 dias de cura e alcançando os melhores resultados de tração entre os testes com substituição do agregado, ficando abaixo apenas do traço de referência nas idades de 14 e 28 dias.

Esse comportamento de redução da resistência mecânica também foi observado em ensaios por outros autores, apesar dos resultados obtidos, essas características não inviabiliza a utilização do concreto com borracha de pneu, apenas direciona a sua utilização em frações menores, como a de $2 \%$, aplicadas em campos da construção civil que não exijam concreto para fins estruturais. Além de representar um ganho ambiental ao destinar resíduos com elevado potencial poluidor.

Diante dos resultados deste trabalho e o obtido em literaturas, recomenda-se ensaios com adoção de distintos critérios para incorporação do resíduo no concreto, haja visto a possibilidade de conciliar a resistência a tração com a resistência a compressão para melhores resultados.

\section{AGRADECIMENTOS}

Agradecemos ao Centro Universitário FG - UniFG, ecossistema Ânima, pelo apoio e subsídios à esta pesquisa.

\section{REFERENCIAS}

Associação Brasileira de Cimento Portland - ABCP. (2002). Guia básico de utilização do cimento Portland. Boletim Técnico. $7^{\mathrm{a}}$ ed. São Paulo, 28 p.

Associação Brasileira De Normas Técnicas. (2016). NBR 5738 - Concreto - Procedimento para moldagem e cura de corpos de prova. Rio de Janeiro, 2016.

Associação Brasileira De Normas Técnicas. (2018). NBR 5739 - Concreto - Ensaio de compressão de corpos de prova cilíndricos. Rio de Janeiro, 2018.

Associação Brasileira De Normas Técnicas. (2009) NBR 7211 - Agregado para Concreto Especificação. Rio de Janeiro.

Associação Brasileira De Normas Técnicas. (2011) NBR 7222 - Concreto e argamassa Determinação da resistência à tração por compressão diametral de corpos de prova cilíndricos. Rio de Janeiro.

Associação Brasileira De Normas Técnicas. (1998). NBR NM 67 - Concreto - Determinação da consistência pelo abatimento do tronco de cone. Rio de Janeiro.

Associação Brasileira De Normas Técnicas. (2003). NBR NM 248 - Agregados - Determinação da composição granulométrica. Rio de Janeiro. 
Associação Brasileira De Normas Técnicas. (2006) NBR NM 45 - Agregados - Determinação da massa unitária e do volume de vazios. Rio de Janeiro.

Associação Brasileira De Normas Técnicas. (2009). NBR NM 52 - Agregado miúdo Determinação da massa específica e massa específica aparente. Rio de Janeiro.

Associação Brasileira De Normas Técnicas. (2009). NBR NM 53 - Agregado graúdo Determinação da massa específica, massa específica aparente e absorção de água. Rio de Janeiro.

Boaventura, M. C. (2011). Avaliação da Resistência à Compressão de Concretos Produzidos com Resíduos de Pneus. Univeridade Estadual de Feirra de Santana. Feira de Santana, 82 p.

Bravo, R. S. (2014). Análise de blocos de concreto com resíduo de borracha de pneu e metacaulim. 63 f. Dissertação (mestrado) - Universidade Estadual Paulista Júlio de Mesquita Filho. Faculdade de Engenharia.

Kurz, M. N.; Brandelli, T. M.; Paliga, C. M. Torres, A. S. (2018). A potencialidade do uso de resíduo de borracha de pneu em argamassa: análise das propriedades físicas e mecânicas. Matéria (Rio de Janeiro), v. 23.

Lagarinhos, C. A. F.; Tenório, J. A. S. (2013). Logística reversa dos pneus usados no Brasil. Polímeros, v. 23, n. 1, p. 49-58.

Martins, P. M. (2013). Concreto com Adição de Borracha, Sucatas de Pneus - Uma Abordagem do Módulo de Elasticidade. Universidade Tecnológica Federal do Paraná. Campo Mourão, p. 47.

São Thiago, P. F. e Bicalho, L. A. (2018). Estudo da Utilização de Agregados de Pneus Inservíveis em Concreto para Aplicação em Pisos Intertravados. Centro Universitário de Volta Redonda. Volta Redonda, $36 \mathrm{p}$.

Simonetti, C. (2020). Avaliação do comportamento ao fogo de placas de vedação de concreto com inserção de resíduos de pneus inservíveis. Repositório Digital da Biblioteca da Unisinos. São Leopoldo.

Verzegnassi, E.; Lintz, R. C. C.; Barbosa, L. A. G.; Jacintho, A. E. P. G. A. (2011). Concreto Convencional com Adição de Borracha Reciclada de Pneus: Estudo das Propriedades Mecânicas. Estudos Tecnológicos - Vol. 7, n², p. 98-108. 